\title{
Mediterranean diet? no, thanks: mediterranean lifestyle!
}

\author{
Samir G. Sukkar
}

(C) Springer-Verlag 2011

Dear readers,

Starting in the 1980s, Ancel Keys and other nutritionists recognised how the Mediterranean diet was able to prevent the cardiovascular conditions, cancers and disorders that result from a diet lacking nutrients essential to health. The basis of such diet is not a geographic location, but the result of historic exchanges between various Countries in the Mediterranean basin, that were established over time in any particular region, with many proposals, products and variants.

The staple foods of the Mediterranean diet comprise wholegrain breads and pastas, cereals, legumes, all kinds of vegetables, fruit in season, fish, aromatic herbs, sheep and goat's milk and cheeses, wine (in moderation) and, above all, olive oil as the main condiment. Meat consumption is reduced and white meat, such as chicken, turkey and rabbit predominate.

Nutritional experts agree that a diet inspired by the principles of the Mediterranean diet is healthy, as is confirmed by studies of populations that are particularly long-lived or protected from degenerative vascular, osteoarticular and neoplastic diseases. This is also a gratifying cuisine with intense flavours and colours.

Scientific studies show that in addition to protecting against cardiovascular and neoplastic diseases, the Mediterranean diet also has potential protective effects on the brain, contributing to the prevention of cognitive decline.

\section{S. G. Sukkar $(\bowtie)$}

Dir. Resp.le U.O.D. Dietetica e Nutrizione Clinica,

Az.Ospedale-Università San Martino di Genova,

Università di Genova, Pad. VII piano $2^{\circ}$, Largo R. Benzi 10,

16132 Genoa, Italy

e-mail:samir.sukkar@hsanmartino.it
It has emerged that people who follow this type of nutritional regimen have a lower probability of cognitive decline [1]. The Mediterranean diet can also reduce the possibility of developing Alzheimer's disease in people showing signs of cognitive difficulty. Adherence to a form of the healthy Mediterranean diet is associated with significant improvement in health as was shown in a study [2] conducted in about 1.5 million people, with a follow-up that varied from 3 to 18 years, in which a reduction of $13 \%$ in both Alzheimer's and Parkinson's diseases, of $6 \%$ in death from cancer, of $9 \%$ for cardiovascular disease and 9\% for death from all causes was demonstrated.

Recently, a study by De Lorenzo et al. has highlighted the positive impact of the organic Mediterranean diet on health (Italian Mediterranean diet as reference) with respect to the conventional diet [3], in terms of reduction of inflammatory status and of endothelial dysfunction associated with obesity and kidney disease. It should also be pointed out, for the first time, that daily consumption of organic foods in the context of the Mediterranean diet could be linked to a reduction in homocysteine, phosphorous, total cholesterol, microalbuminuria, and to an increase in circulating vitamin $B_{12}$ levels [4]. Moreover, in a follow-up clinical study, the Mediterranean diet combined with broader lifestyle changes improved renal arterial circulation in essential hypertension. This occurs through the reduction in intra-renal resistance, and does not involve modification of insulin resistance [5]. Through this vascular mechanism, the Mediterranean diet seems to be able to modify an important component of the pathophysiology of arterial hypertension and atherosclerosis.

In the long-term, personal behaviours and the lifestyle adopted, environmental and socioeconomic conditions have been shown to be the most important factors both for life expectancy and for health [6]. 
Adopting a lifestyle that preserves vascular integrity is a protective factor against cardiovascular diseases and preserves mental lucidity through the years. In general, the risk factors for cardiovascular pathologies can be divided into modifiable, non-modifiable and partially modifiable ones. Obesity, hypercholesterolaemia, arterial hypertension and physical inactivity belong to the first category.

In Italy, according to ISTAT data, cardiovascular pathologies are responsible for $44 \%$ of all deaths [7]. The most common forms are myocardial infarction and stroke. The basic lesion common to all vascular diseases is atherosclerosis.

Therefore, the identification of risk factors for cardiovascular conditions plays a fundamental role in the prevention of serious acute vascular events. In the 1970s, the conclusion was already made that high serum cholesterol was one of the major risk factors for cardiovascular conditions [8]. It was also revealed that an excess of LDL cholesterol is the consequence of a sedentary lifestyle and of a diet in which refined foods, animal fats and simple sugars predominate. Instead, high levels of HDL cholesterol are associated with a healthy lifestyle and a diet rich in vegetable fibre and complex carbohydrates. More recently, it has emerged that a deficiency of antioxidant substances in the diet, in particular vitamin E, is an additional and significant cardiovascular risk factor $[9,10]$.

The basic mechanism responsible for atherosclerosis is chronic inflammation of the blood vessels, associated with high cholesterol and hypertension. Inflammation results from excessive eicosanoid and prostaglandin production, substances that trigger the inflammatory process. The release of large quantities of eicosanoids is primarily due to a diet rich in saturated fats of animal origin. To prevent cardiovascular pathologies, it is necessary to reduce saturated fat intake and increase that of the essential omega-3 fatty acids present in fish, oilseeds and nuts [11].

Physical activity has a favourable effect on the prevention of cardiovascular diseases, even if some general recommendations should be respected.

The intensity, duration and frequency of activity should be adapted to the individual.

Physical exercise influences and modifies multiple hormone systems. Regular physical activity reduces excess glucose and insulin in the blood [12]. While normalisation of insulin levels and an improving tissue response to it contribute to favouring longevity; physical efficiency is assured by adequate muscular tone.

Laboratory studies and numerous observations on the population have helped define the nature of cancer, part genetic and part environmental, specifying the role of factors that favour or inhibit the neoplastic process [13]. According to AICR (American Institute for Cancer Research), it is understood that more than $30 \%$ of tumours are the consequence of our diet. In particular, the US National Cancer Institute (NCI) developed its "5-a-day" dietary education programme in 1991 with the aim of increasing the consumption of fruit and vegetables to five portions a day. Nowadays, after 20 years, the 5-a-day axiom remains valid and the Mediterranean diet represents the most tightly linked model to these concepts [14].

Restriction of caloric intake consistent with individual energetic needs, maintenance of body shape and weight, regular consumption of fruits and vegetables rich in fibre and protective antioxidant micronutrients, a preference for food with a low glycaemic index, reduction in animal fats, intake of omega-3 fats, moderate consumption of alcoholic beverages, cessation of smoking, regular moderate physical activity, periodic medical examinations, assumption of the right lifestyle and a healthy diet, can help avert the numerous and repetitive attempts at formation of tumour cell clones [15].

Specifically, the regular and abundant daily assumption of the protective substances present in food not only neutralises free radicals that cause cellular damage, but also intervenes selectively and specifically in the genesis, development, growth and diffusion phases of the process of tumorigenesis [16].

The major active components capable of preventing DNA damage and the uncontrolled multiplication of cells that leads to tumour formation are mainly present in garlic, cabbage and cruciferous vegetables in general. They comprise ellagic acid, sulforaphane, indole-3-carbinol and diallyl sulphur.

Other substances belonging to the polyphenol group, such as curcumin of turmeric, soy genistein, tomato lycopene, resveratrol from red wine, epigallocatechin from green tea, can counteract tumour growth by interfering with cell replication and slowing or blocking its growth.

Another group of molecules acts mainly by blocking angiogenesis, required to guarantee tumour growth and spreading. These are omega-3 fatty acids, limonene from citrus fruits, ellagic acid, and the anthocyanidine and protocyanidine abundantly present in berries.

The role of free radicals, responsible for a slow, continuous attack on DNA and cellular structures, is fundamental in the ageing process. Even though the body has internal defensive mechanisms, it is mainly food that insures protection against damage from oxidative stress [17]. In particular, consumption of legumes, vegetables, fruits, cereals, assures the uptake of flavonoids with antioxidant activity. On the other hand, animal-derived foods are lacking in these. Deactivating and neutralising free radicals is required for the uptake of micronutrients that protect the cells, such as vitamins A, C, E, some oligo elements (zinc, selenium), amino acids (cysteine, methionine) and enzymes [18], and many other natural antioxidant non-nutrients. 
All of this is maximally favoured by the Mediterranean diet.

In addition, the Mediterranean diet does not comprise only food, but also requirements linked to agriculture, methods and choices for ethical and responsible raising of livestock, the type and choice of fish, respect for the seasons, food preparation, choice of condiments, etc.

In the Mediterranean diet, rules are set that belong to a healthy lifestyle, that is, the main meals are distributed at three times during the day: breakfast, lunch and dinner, with fruit or vegetable-based snacks interspersed. In the Mediterranean world, where the concept of slow food recently emerged, meals are consumed in tranquillity and possibly in a convivial environment, since food is also this.

All of this is a true philosophy of life that recalls the true meaning of the word diet and derives from the Greek diaita $\left(\delta^{\prime}\langle\alpha \imath \tau \alpha)\right.$, which actually means rule of life, way of living, lifestyle. The Mediterranean diet "is much more than simply food". It promotes social interaction, since common ground is the basis of social customs and of the festivities shared by a given community, and has given rise to a great body of knowledge, songs, proverbs, tales and legends. The Diet is based on respect for the territory and biodiversity, and guarantees the conservation and development of traditional activities and of trades linked to fishing and agriculture in the communities of the Mediterranean." [19].

The word Diet is used not in its medical significance as nutritional therapy, but in a much wider sense comprising lifestyle and ethnic belonging, through which many populations can aspire to be inspired to improve their quality of life.

For this reason, our scientific society ADI has chosen this theme for the National course to be held in Rome next Fall.

S. G. Sukkar Editor-in-Chief

Conflict of interest None.

\section{References}

1. Scarmeas N, Stern Y, Mayeux R, Manly JJ, Schupf N, Luchsinger JA (2009) Mediterranean diet and mild cognitive impairment. Arch Neurol 66(2):216-225

2. Sofi F, Cesari F, Abbate R, Gensini GF, Casini A (2008) Adherence to Mediterranean diet and health status: meta-analysis. BMJ 11:337-344
3. De Lorenzo A, Alberti A, Andreoli A, Iacopino L, Serranò P, Perriello G (2001) Food habits in a southern Italian town (Nicotera) in 1960 and 1996: still a reference Italian Mediterranean diet? Diabetes Nutr Metab 14(3):121-125

4. De Lorenzo A, Noce A, Bigioni M, Calabrese V, Della Rocca DG, Di Daniele N, Tozzo C, Di Renzo L (2010) The effects of Italian Mediterranean organic diet (IMOD) on health status. Curr Pharm Des 16(7):814-824

5. Trovato GM, Pirri C, Martines GF, Tonzuso A, Trovato F, Catalano D (2010) Lifestyle interventions, insulin resistance, and renal artery stiffness in essential hypertension. Clin Exp Hypertens 32(5):262-269

6. Notarbartolo A, Barbagallo CM Prevenzione globale del rischio cardiovascolare: abitudini di vita e alimentazione, pp 125$151 \mathrm{http}: / /$ www.erboristeria.org.uk/files/alimentazione_salute_e_ benessere.pdf\#page $=126$

7. Ministero della Salute. http://www.salute.gov.it/dettaglio/pdPrimo Piano.jsp?id $=200 \&$ sub $=7 \&$ lang $=$ it

8. Keys A (1970) Coronary heart disease in seven countries. Circulation 41(1):186-195

9. Kris-Etherton PM, Lichtenstein AH, Howard BV, Steinberg D, Witztum JL (2004) Antioxidant vitamin supplements and cardiovascular disease. Circulation 110:637-641

10. Joshipura KJ, Hu FB, Manson JE, Stampfer MJ, Rimm EB, Speizer FE, Colditz G, Ascherio A, Rosner B, Spiegelman D, Willett WC (2001) The effect of fruit and vegetable intake on risk for coronary heart disease. Ann Intern Med 134(12):1106-1114

11. Singh RB, Dubnov G, Niaz MA, Ghosh S, Singh R, Rastogi SS, Manor O, Pella D, Berry EM (2002) Effect of an Indo-Mediterranean diet on progression of coronary artery disease in high risk patients (Indo-Mediterranean Diet Heart Study): a randomised single-blind trial. Lancet 360:1455-1461, 1469

12. Lindström J, Louheranta A, Mannelin M, Rastas M, Salminen V, Eriksson J, Uusitupa M, Tuomilehto J (2003) The Finnish Diabetes Prevention Study (DPS): lifestyle intervention and 3-year results on diet and physical activity Diabetes Care 26(12): $3230-3236$

13. Ahmed FE (2004) Effect of diet, life style and other environmental/chemoprotective factors on colorectal cancer development and assessment of the risks. J Environ Sci Health C Environ Carcinog Ecotoxicol Rev 22(2):91-147

14. Sukkar SG (2009) What about "5-a-day" dietary education programme 20 years later? The five colours of cancer and obesity prevention. Mediterr J Nutr Metab 2:85-87

15. Trichopoulou A, Lagiou P, Kuer H et al (2000) Cancer and mediterranean dietary traditions. Cancer Epidemiol Biomarkers Prev 9(9):869-873

16. Hanausek M, Walaszek Z, Slaga TJ (2003) Detoxifying cancer causing agents to prevent cancer. Integr Cancer Ther 2(2): 139-144

17. Di Renzo L, Di Pierro D, Bigioni M, Sodi V, Galvano F, Cianci R, La Fauci L, De Lorenzo A (2007) Is antioxidant plasma status in humans a consequence of the antioxidant food content influence? Eur Rev Med Pharmacol Sci 11(3):185-192

18. Martínez ME (2005) Primary prevention of colorectal cancer: lifestyle, nutrition, exercise. Recent Results Cancer Res Tumor Prev Genet III 166:177-211

19. CNI-UNESCO La Dieta Mediterranea è patrimonio immateriale dell'Umanità http://www.unesco.it/cni/index.php/archivio-news/ 174-la-dieta-mediterranea-e-patrimonio-immateriale-dellumanita 